\title{
Belphégor
}

\section{Trudel, Jean-Louis, Petit guide de la science-fiction au Québec}

\section{Sophie Beaulé}

\section{(2) OpenEdition}

1 Journals

\section{Electronic version}

URL: https://journals.openedition.org/belphegor/2108

DOI: $10.4000 /$ belphegor.2108

ISSN: $1499-7185$

Publisher

LPCM

\section{Electronic reference}

Sophie Beaulé, "Trudel, Jean-Louis, Petit guide de la science-fiction au Québec", Belphégor [Online], 18-1 | 2020, Online since 04 March 2020, connection on 30 June 2021. URL: http://journals.openedition.org/ belphegor/2108 ; DOI: https://doi.org/10.4000/belphegor.2108

This text was automatically generated on 30 June 2021.

\section{(c) (i) (9)}

Belphégor est mis à disposition selon les termes de la Licence Creative Commons Attribution - Pas d'Utilisation Commerciale - Pas de Modification 4.0 International. 


\section{Trudel, Jean-Louis, Petit guide de la science-fiction au Québec}

\section{Sophie Beaulé}

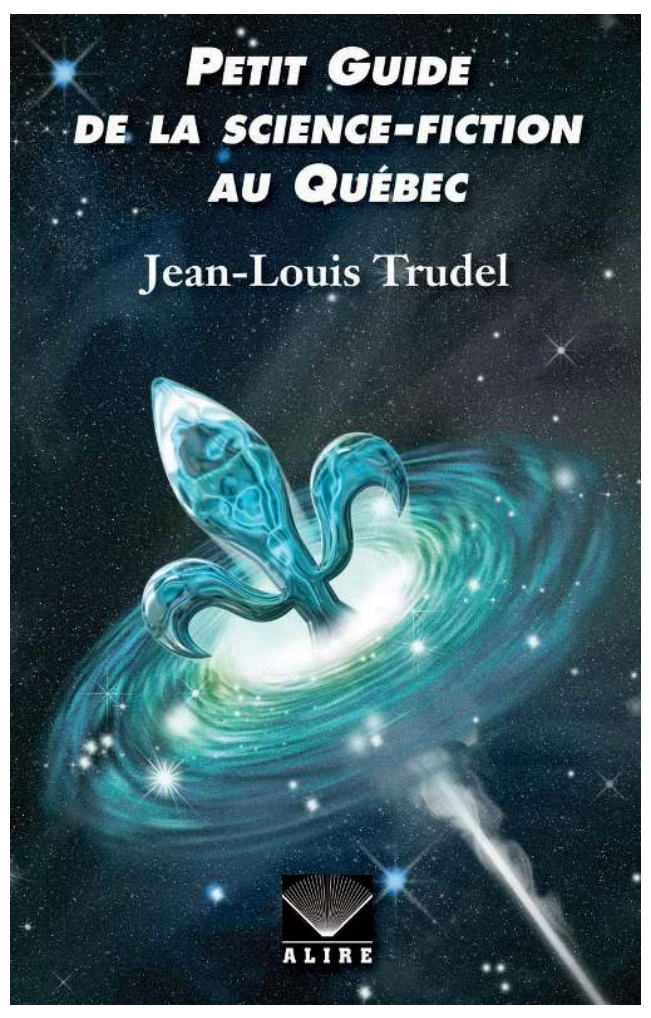

$1 \quad$ Pourquoi un guide de la science-fiction québécoise (sfq) ? C'est que le genre apparaît plus important au Québec qu'on ne le penserait a priori. Près de 800 auteurs ont publié au moins un texte entre le XIXe siècle et le nouveau millénaire; voilà qui n'est pas négligeable. L'écrivain plusieurs fois primé, traducteur et historien de la littérature Jean-Louis Trudel propose un guide très fouillé - sans viser l'exhaustivité - de la production québécoise, un objet d'exploration pour le lecteur général et de référence pour les aficionados. 
Divisé en sept chapitres abondamment illustrés, l'ouvrage se révèle très riche sur le plan du contenu. Il suit l'évolution du genre en la replaçant dans les contextes social, politique et culturel québécois, en plus de la situer par rapport aux productions française et anglo-américaine. En outre, la présentation des œuvres s'accompagne de commentaires biographiques et d'une analyse des conditions de production et de réception, tout en relevant la présence du genre dans différents médias tels que la bande dessinée et la radio. Une bibliographie critique succincte, des annexes et un index complètent l'ouvrage. Notons enfin que le guide se consacre exclusivement aux écrivains québécois, ce qui exclut des auteurs tels qu'Annick Perrot-Bishop, Vittorio Frigerio, Maurice Dantec et Trudel lui-même.

3 C'est à Napoléon Aubin, un calviniste d'origine suisse, que l'on doit la première fantaisie utopique, «Le Plan de la République canadienne» (1838), et le premier feuilleton (incomplet) de science-fiction, «Mon voyage de Québec à la Lune » (1839). L'intérêt pour la politique-fiction donne, en 1880, la première nouvelle d'anticipation, «La tête de saint Jean-Baptiste ou Légende pour nos arrière-petits-neveux en 1980 » de Wenceslas-Eugène Dick. Le premier roman d'anticipation apparaît cinq ans plus tard sous la plume de Jules-Paul Tardivel, Pour la patrie. Cet écrivain se montre d'ailleurs plus audacieux sur le plan science-fictionnel que la première uchronie québécoise, Similia similibus, ou la guerre au Canada (1916) d'Ulrich Barthe. Trudel souligne que la rencontre du spéculatif et du religieux constitue une spécificité de la sfq du XIXe siècle.

4 La popularité de Jules Verne atteint aussi le Québec; l'écrivain français influence des auteurs comme Emmanuel Desrosiers avec sa Fin de la Terre (1931). Parallèlement aux revues et journaux dispensateurs de feuilletons, la province accueille plus tard la production bon marché des États-Unis. En général le genre ne jouit pas de la reconnaissance institutionnelle ni ne s'épanouit durant la période couvrant la fin du XIXe siècle à la Deuxième Guerre mondiale, voire aux années 1960. Parmi les rares productions, Trudel relève entre autres La Cité dans les fers (1926) d'Ubald Paquin, la série «Les aventures futuristes de deux savants canadiens-français » (1949) de Pierre Daigneault, ainsi que la première bande dessinée de sfq, Les Deux petits nains (1947-1949) de Paulin Lessard.

5 Le vent tourne avec la fin des années 1950 et s'affirme dans la décennie suivante ; c'est à ce moment que débute la sfq moderne. Le genre se déploie d'abord dans la littérature pour jeunes, d'où ressortent des œuvres telles que Quatre Montréalais en l'an 3000 de Suzanne Martel (1963) ou la série « Unipax » (1965-1968) de Maurice Gagnon. Il profite également de la fortune dont jouissent la nouvelle et le roman, ainsi que d'autres médias, au point que Trudel parle d'une imprégnation de la culture québécoise. Dans les années 1970, la sf se prête aux projets expérimentaux (Roger Des Roches), féministes (Louki Bersianik) ou ésotériques. Elle profite aussi d'influences et de collaborations internationales - on pense, par exemple, à l'opéra rock Starmania (1978). Enfin, elle prend la forme de la politique-fiction, dans le sillage nationaliste. L'écrivain majeur de cette décennie est sans conteste Jacques Brossard, dont l'œuvre sera publiée plus tard.

6 La période 1974-1986 est d'autant plus importante qu'elle voit la constitution de la "génération Vonarburg ", ainsi nommée par Trudel pour le rôle central de pionnière et d'animatrice que joue Élisabeth Vonarburg dans le milieu sffq (science-fiction et fantastique québécois). L'historien consacre un chapitre entier à ces auteurs. Outre Vonarburg, Esther Rochon, Jean-Pierre April, Alain Bergeron, Daniel Sernine, Joël Champetier et Yves Meynard (auxquels on devrait ajouter Trudel) créent des œuvres 
qui enrichissent le corpus québécois tout en participant à l'évolution de la sf transnationale.

7 Le chercheur revient ensuite sur les structures du milieu sffq depuis le "point d'inflexion» de 1974. Un sous-champ culturel avec ses lieux de socialisation (les congrès Boréal) et des instances de production et de légitimation se cristallise rapidement. Celles-ci apparaissent sous la forme de prix et des compilations de L'Année de la sffq, puis du DALIAF (Claude Janelle, 2011). Les instances de production s'orientent selon quatre groupes entre le début des années 1960 et le début des années 1980. D’abord, «Les écrivains institutionnels » légitiment la sf ; ils sont issus des littératures populaire, de jeunesse et surtout avant-gardiste, où Louis-Philippe Hébert tient une place centrale. Ensuite, les collaborateurs de Requiem (1974-1979), autour de Norbert Spehner, stimulent un mouvement littéraire. La revue devient Solaris et passera au format livre en 2000. Un troisième groupe crée la revue Pour ta belle gueule d'ahuri (1979-1983) qui lance des artistes. Enfin, le groupe de la revue imagine... (1979-1997/8) avec entre autres Jean-Marc Gouanvic comme directeur, représente selon Trudel l'essai le plus ambitieux pour élaborer une littérature de sfq.

Trudel examine aussi d'autres instances de production, des fanzines à la micro-édition et à l'édition spécialisée. Celle-ci démarre en 1974 avec une collection pour adultes, «Demain Aujourd'hui » des éditions Helios. Suivent d'autres collections à la durée variable. Après la disparition de "Sextan", son directeur Jean Pettigrew cofonde les éditions Alire, qui a publié entre 1996 et 201643 romans, 8 recueils de nouvelles - la collection "Nouvelles" se révèle d'ailleurs l'une des plus riches de l'histoire québécoise, déclare le critique - ainsi que des essais et les compilations mentionnées plus haut. Dans les années 2000 apparaissent des lieux de production intra et horsmilieu, tels que les éditions des Six Brumes, et des anthologies (plus d'une vingtaine entre 1983 et 2014).

9 La sf imprègne plus que jamais la culture du nouveau millénaire. Au Québec, les rassemblements faniques témoignent de l'engouement pour la culture geek. De plus, des séries télévisées, des webséries, des bandes dessinées et des films québécois apparaissent. Du côté littéraire, une partie de la production migre hors du milieu. Ses écrivains proposent des œuvres appartenant généralement à la dystopie, à l'apocalyptique (Ariane Gélinas) et surtout à la politique-fiction (Mathieu Blais et Joël Casséus) dans un cadre québécois, ce qui amène Trudel à déclarer que c'est désormais moins une génération d'auteur qu'une thématique qui s'impose. Le critique parle d'une "nouvelle science-fiction politique québécoise» qui exprime les angoisses contemporaines et le désir d'un renouvellement. Avec la religion, la politique-fiction se révèle ainsi une constante de la sfq depuis Napoléon Aubin.

10 Avec son Petit guide, Trudel porte un éclairage aussi érudit qu'agréable à lire sur un aspect moins connu de la littérature québécoise. À joindre absolument aux côtés des anthologies et histoires littéraires du Québec - et du genre conjectural. 


\section{AUTHOR}

SOPHIE BEAULÉ

Saint Mary's University 